\title{
Prospective cohort study on 500 MIS $\circledast$ implants: Success rate, biological and technical complications: 1 year follow-up.
}

\author{
Ragucci GM*, Giralt-Hernando $\mathrm{M}^{\star}$, Méndez-Manjón I*, Guijarro-Martínez R*, \\ Hernández-Alfaro $F^{*}$ \\ *International Master In Oral Surgery (IMOS).Departamento de Cirugía Oral y Maxilofacial. Universidad Internacional de Cataluña. Barcelona.
}

\section{INTRODUCTION}

Implant therapy for replacing missing teeth is a predictable treatment with a high survival rate in the long term. However, some failures are seen during the first year after implant placement. Previous studies have been related the history of periodontitis, smoking habit and a poor oral hygiene with a higher risk to develop periimplantitis. However, more research is necessary in this regard to identify and consequently control all the conditions that can affect the long-term success of implant therapy.

\section{OBJECTIVE}

The aim of this study was to establish a standardized method to evaluate the long-term results of MIS® implants (V3 and $\mathrm{C} 1$ ), in terms of survival, and to assess the risk factors associated with biological and technical complications. We aim to study the results of different surgical scenarios and patient-related factors and, therefore, identify their influence for the long-term stability of the treatment.

\section{MATERIAL AND METHODS}

A prospective cohort study with five hundred implants (C1 and V3 MIS ${ }^{\circledR}$ ) was conducted in patients older than 18 years old scheduled for implant therapy. Each patient was carefully informed about the objectives of the study and the informed consent was signed. All the surgeries were performed by postgraduate students at the UIC (International University of Catalonia). Patient-related and surgical related factors of each patient were saved in our database to test their influence in the long-term survival of the implants
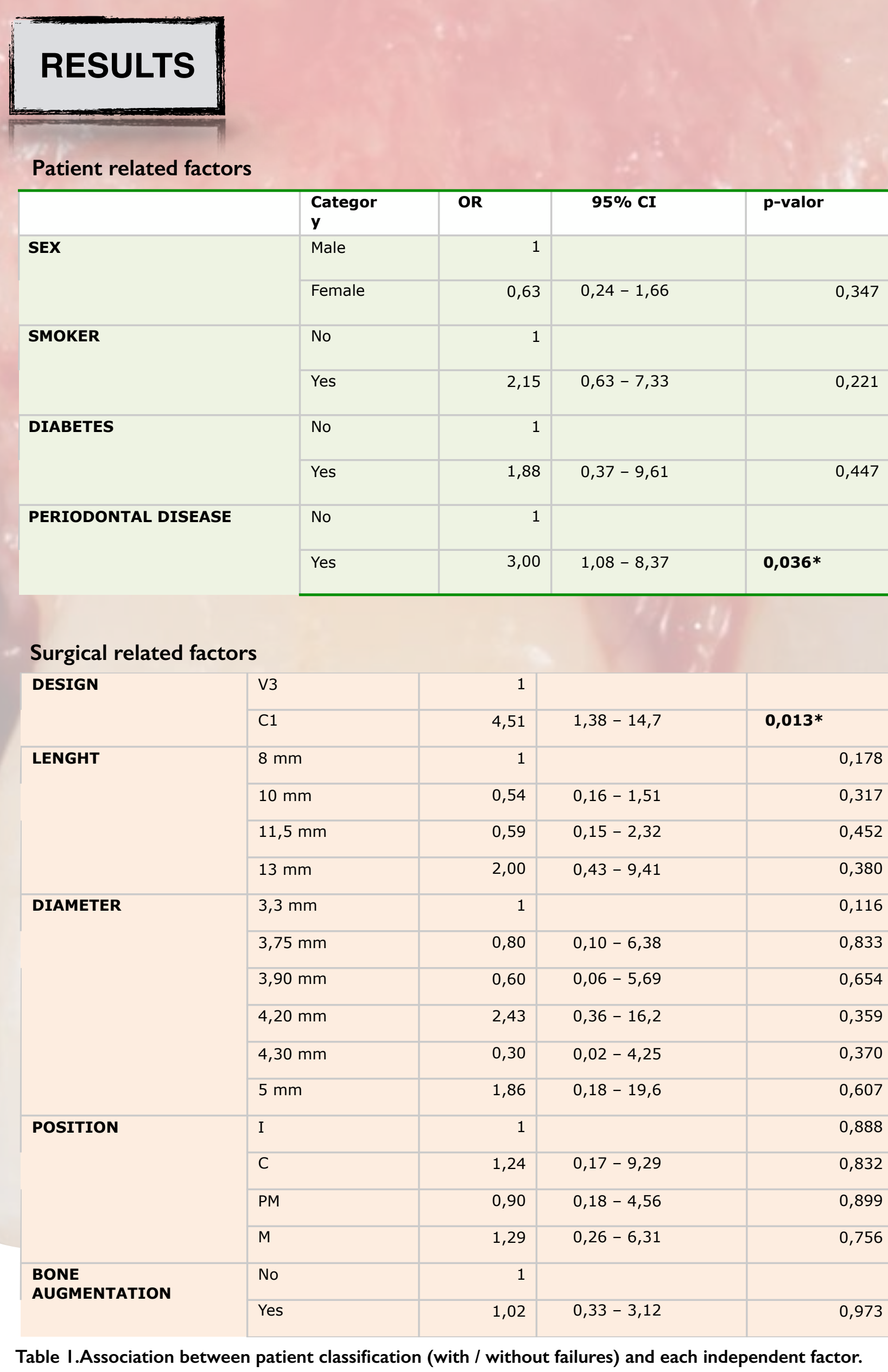

\section{CONCLUSIONS}

After 1-year of follow-up, $4.2 \%$ of 501 implants had failed; which were considered early failures; without osseointegration of the implant. No prosthetic or biologic complications were found. History of periodontal disease was significantly related with higher implant failure (OR:3.00). 